\title{
EVALUATION OF CREEP PROPERTY OF AS800 SILICON NITRIDE FROM AS- PROCESSED SURFACE REGIONS
}

\author{
H. T. Lin, S. B. Waters, and K. L. More, Metals and Ceramics Division, Oak Ridge National \\ Laboratory, Oak Ridge, TN 37831-6068
}

J. Wimmer and C. W. Li, Honeywell Ceramic Components, Torrance, CA 90504

\begin{abstract}
Tensile creep studies were carried out to evaluate the creep performance of AS800 silicon nitride samples extracted from the surface and bulk regions of as-processed billets at $1350^{\circ} \mathrm{C}$ in air. The objective of this study was to understand the creep properties of the silicon nitride in the as-processed surface region and determine if they are comparable to those obtained from the bulk region. The results indicated that samples from the as-processed surface region exhibited higher creep rates and shorter lifetimes as compared with those obtained from the bulk region. The poor creep performance of material from the as-processed surface region was due to the higher content of glassy phase enriched with oxygen and sintering additive elements.
\end{abstract}

\section{INTRODUCTION}

Silicon nitride ceramics with an in-situ reinforced microstructure consisting of elongated grains have been the primary candidates for advanced turbines and microturbines applications due to their excellent thermomechnical properties (e.g., strength, fracture toughness, and fatigue and creep resistance) [1-4]. Various ceramic components, e.g., turbine blades, nozzles, and turbo compressors, have been mass produced for actual component application or field tests [5-7]. However, it should be noted that processing steps in production line and/or chemical compositions employed sometimes need to be modified to achieve consistent mechanical properties of components with complex shapes. Therefore, a key issue in the development of ceramic components is to evaluate the mechanical properties of complex shaped components and determine if these are comparable to those obtained from simple test coupons utilized in the development of ceramic materials.

The airfoil region in the ceramic components is typically often subjected to high temperature and high stress during operation. Therefore, the lifetime of the components would be governed by the long-term mechanical reliability and chemical stability of airfoil section under the application environments. A test methodology has been developed to extract samples (e.g., small dog-bone type creep specimens and biaxial disks) from complex shaped airfoils [8,9]. The mechanical properties, as well as the microstructure, of airfoils before and after engine field tests can then be evaluated and compared. The alternative to the evaluation of complex shaped airfoils is to fabricate simulated airfoil plates with final thickness similar to that of the airfoils or machine creep samples from the asprocessed surface regions. These alternatives could provide indirect approaches to evaluate the properties of complex shaped components, which are not always readily accessible otherwise. They also offer a useful means to assess whether the processes and/or chemical compositions employed in component production line achieve mechanical properties consistent with those developmental materials. The present study was carried out to determine the creep properties for samples machined from as-processed surface region and bulk region of a commercially available AS800 silicon nitride. 
The creep results will be compared and discussed based on the analyses of microstructure and chemistry for the elongated silicon nitride grains and secondary phase(s), respectively.

\section{EXPERIMENTAL PROCEDURES}

The commercially available AS800 silicon nitride ceramic billets evaluated in the present study was fabricated via a slip-cast plus gas pressure sintering (GPS) processes with rare earth oxides sintering additives. In general, the as-sintered billets exhibited of a yellowish surface layer with a typical thickness of 2-3 mm and a gray interior region (Fig. 1). The yellowish appearance was also observed in all as-processed AS800 silicon nitride components (i.e., turbine blades and vanes) that were designed and fabricated for advanced turbines.

The dog-bone type tensile creep specimens, similar to NIST SR50 [10], were machined from both the as-processed surface layer and bulk region (Fig. 1). The location of each tensile specimen in the billets was also carefully tracked to assess the uniformity of the creep properties. Tensile creep tests were carried out in a high temperature creep frame with a pneumatic-type loading system. The tensile stress was applied to creep specimens via sintered $\alpha-\mathrm{SiC}$ pins and pull rods. The applied stress was continuously monitored and controlled using a personal computer with a LabView application program (National Instruments, Austin, TX). The creep displacement was measured by an optical-based laser extensometer equipped with a water-cooled laser path shield. The resolution of laser extensometer at test temperature is $\pm 0.5 \mu \mathrm{m}$, which is limited by the data microprocessor. The details of tensile creep test procedures can be found in Ref. [11].

Analyses of elongated grain microstructure and secondary phase(s) were carried out via X-ray and scanning electron microscopy on materials from the as-processed surface layer and bulk region. These analyses aimed to determine whether there were major variations in size and distribution of elongated grains and secondary phase(s) prior to the tensile creep testing. SEM analysis of fracture surfaces of crept samples was also conducted to understand the creep controlling as well as life limiting processes.

\section{RESULTS AND DISCUSSION}

The X-ray analyses of as-received AS800 silicon nitride indicated the dominant secondary phase $\left(\sim 10 \%\right.$ of total) present was a variant of $\mathrm{Y}_{10} \mathrm{Si}_{7} \mathrm{~N}_{4} \mathrm{O}_{23}$ commonly designated as the H-Phase. The dominant crystalline $\mathrm{H}$-phase present was the same in both as-processed surface layer and bulk region. In addition, a quantitative analysis of twenty SEM micrographs consisting of $\sim 800$ grains in total showed that the amount, spatial distribution, and size distribution of the elongated grains in the surface layer region were similar to those observed in the bulk region. For instance, materials in surface layer and bulk region all exhibited a fine grained matrix with grain size of $\sim 0.5 \mu \mathrm{m}$ and a population $(\sim 15-$ $20 \%$ ) of large elongated grains with grain size $\sim 1.5-2.0 \mu \mathrm{m}$. The aspect ratio of elongated grains ranged from 5 to 12 in both material regions. Therefore, there are no differences in secondary phase and elongated grain microstructure, which can be key factors governing the high-temperature creep performance. Note that the mechanical testing at room temperature showed that the material from surface layer region exhibited flexural strength $(800 \mathrm{MPa})$ and Weibull modulus $(\mathrm{m}=18)$ similar to those obtained from the bulk region (760 MPa and $\mathrm{m}=15)$ [12].

Figure 2 showed the creep rates versus applied stress results of AS800 silicon nitride samples machined from as-processed surface layer and bulk region at $1350^{\circ} \mathrm{C}$ in air. The results indicated that, despite the similarity in secondary phase and elongated grain microstructure, samples machined from surface layer region exhibited creep rates that were 10-20 times higher than those from the bulk region (Fig. 2a). The results also showed that the material from surface layer region exhibited a much higher stress exponent $(\mathrm{n} \sim 16.5)$ than the value obtained from bulk material $(\mathrm{n} \sim 5)$. Note that the stress exponent of 5 obtained for the material from the bulk region in the present study is similar to those reported for silicon nitride materials containing similar sintering additives [13]. The higher $n$ values obtained for silicon nitride ceramics and ceramics containing liquid phase(s) are generally attributed to 
enhanced creep deformation and cavitation [14-16]. In addition, the materials from the surface region exhibited 10-30 times shorter lifetimes as compared with those from bulk region under the same applied stress level (Fig. 2b). The observed significant differences in creep performance between surface layer and bulk material led one to surmise that there were due to the variations in microstructure (e.g., percent of crystalline phase) and chemical composition of secondary phase(s) that could not be detected by X-ray and SEM analysis. Transmission electron microscopy (TEM) analysis was, therefore, carried out to gain insight into the key factors that could result in the significantly different creep performance observed.

Figure 3 compares the TEM results of material from the as-processed surface layer and bulk region. TEM examinations showed that there was substantial amount ( $35-40 \%)$ of oxynitride glass in the form of pockets present both between $\mathrm{Si}_{3} \mathrm{~N}_{4}$ grains and surrounding crystalline $\mathrm{H}$-phase pockets at the multiple grain junctions of surface layer materials (Fig. 3a). On the other hand, only crystalline Hphase was observed in the multiple grain junctions of bulk material (Fig. 3b). Note that there is still a thin oxynitride glassy film $(\sim 1-2 \mathrm{~nm})$ present along the two-grain boundaries in both surface layer and bulk material region. The chemical analysis indicated that the oxynitride glassy phase in the surface layer region exhibited a much higher oxygen content plus sintering additives as compared to the contents of crystalline H-phase pockets in either surface layer or bulk region. The presence of the high amount of oxynitride glassy pockets in the surface layer region was presumably due to the incomplete crystallization of secondary phase upon the completion of the sintering cycle. An increase in oxygen content is known to significantly decrease the softening temperature and, also, viscosity of oxynitride glasses due to the more formation of less rigid and crosslinking glass network [17,18]. This was consistent with the observed fracture surfaces of samples from surface layer region, which was covered by a glassy film associated with gas voids (Figure 4a). The glassy surface feature was in sharp contrast with those observed on the fracture surface of samples from the bulk region test under the same test conditions (Fig. 4b). The feature of glassy fracture surface suggested that the oxynitride glassy pockets in as-processed surface layer region probably changed into a liquid-like state at test temperature, permitting creep deformation processes readily to proceed. Furthermore, the inward diffusion of oxygen and consequent oxidation of secondary amorphous phase, as evident of gas voids, would further alter and decrease the viscosity of the glass, thus accelerating the creep process.

Creep deformation in silicon nitride ceramics has been generally attributed to the diffusional mechanisms of solution/precipitation, viscous flow, and grain boundary sliding [19-21]. Since the microstructure of elongated grain content and size distribution was similar, therefore, one could conclude that the observed higher creep rates plus shorter lifetimes of specimens machined from the as-processed surface layer region is due to presence of a high content of oxynitride glass. The softening of the oxynitride glassy phase at the test temperature would allow the solution and precipitation and/or grain boundary sliding processes to occur readily, resulting in higher creep rates and shorter lifetimes. Also, the incorporation of additional oxygen into the glassy phase pockets during creep testing could greatly promote the creep processes due to the further decrease in viscosity, enhancing creep deformation rates as indicated in previous studies [22,23]. The present study clearly demonstrated that the material machined form the same billets may not necessarily exhibit similar creep properties due to the difference in microstructure and chemistry of secondary phase(s). Therefore, a modification on the sintering environment and/or sintering steps is needed to achieve a complete crystallization of secondary phase in surface layer material and, thus, consistent mechanical performance and reliability. It is also critical that a ceramic components database needs to be developed, in addition to the database of developmental materials, to ensure an accurate lifetime prediction results and for structural design capabilities. 


\section{SUMMARY}

Tensile creep studies on materials machined from as-processed surface layer and bulk region were carried out at $1350^{\circ} \mathrm{C}$ in air. Analysis of X-ray and SEM showed that materials from surface layer region exhibited similar elongated grain microstructure and crystalline $\mathrm{H}$-phase to the materials in the bulk region. Tensile creep results showed that samples from the as-processed surface region exhibited higher creep rates and, thus, shorter lifetimes than the samples obtained from the bulk region. The poor creep performance of material from the as-processed surface region was due to the higher amount of glassy phase enriched with oxygen and sintering additive elements, as identified by TEM analysis. The presence of oxygen-enriched glassy phase, which softens at the test temperature, accelerated the creep deformation processes of solution/precipitation, viscous flow, and grain boundary sliding, resulting in poor high-temperature mechanical performance.

\section{ACKNOWLEDGEMENTS}

The authors thank Drs. M. Lance, T. N. Tiegs, and P. F. Becher for reviewing the manuscript. Research sponsored by the U.S. Department of Energy, Office of Power Technologies, Microturbine Technologies Program, under Contract DE-AC05-00OR22725 with UT-Battelle, LLC.

\section{REFERENCES}

${ }^{1}$ D. Anson, K. S. Ramesh, and M. DeCorso, "Application of Ceramics To Industrial Gas Turbines"; DOE/CE/40878-1\&2; Battelle Columbus, March 1991.

${ }^{2}$ H. E. Helms, R. A. Johnson, and L. E. Groseclose, "AGT 100-Advanced Gas Turbine Technology Development Project," pp. 137-155 in Proc. 23rd Automotive Technology Development Contractors' Coordination Meeting P-165, Warrendale, PA, March (1986).

${ }^{3}$ M. van Roode, "Ceramic Retrofit Program," pp. 77-93 in Proc. Joint Contractors Meeting: FE/EE Advanced Turbine Systems Conference FE Fuel Cells and Coal-Fired Heat Engines Conference, DOE/METC-93/6132 (1993).

${ }^{4}$ D. Carruthers and L. Lindberg, "Critical Issues for Ceramics for Gas Turbines," pp. 1258-1272 in Proc. 3rd Int. Symp. on Ceramic Components and Materials for Engines, Westerville, Ohio (1988).

${ }^{5}$ V. Parthasarathy, M. van Roode, J. Price, S. Gates, S. Waslo, and P. Hoffman, "Review of Solar's Ceramic Stationary Gas Turbine Development Program," pp. 259-264, in the Proceedings of the 6th International Symposium on Ceramic Materials and Components for Engine, eds, K. Niihara, S. Kanzaki, K. Komeya, S. Hirano, and K. Morinaga (1997).

${ }^{6} \mathrm{M}$. Hattori, T. Yamamoto, and K. Watanabe, "Development of Ceramic Gas Turbine Components for the CGT301 Engine," pp. 222-227, , in the Proceedings of the 6th International Symposium on Ceramic Materials and Components for Engine, eds, K. Niihara, S. Kanzaki, K. Komeya, S. Hirano, and K. Morinaga (1997).

${ }^{7}$ T. Nakashima, T. Tatsumi, and I. Takehara, "Research and Development of CGT302," pp. 233236, in the Proceedings of the 6th International Symposium on Ceramic Materials and Components for Engine, eds, K. Niihara, S. Kanzaki, K. Komeya, S. Hirano, and K. Morinaga (1997).

${ }^{8}$ H. T. Lin, P. F. Becher, M. K. Ferber, and V. Parthasarathy, "Verification of Creep Performance of a Ceramic Gas Turbine Blade," Key Engineering Materials, Vol. 161-163, 671-674 (1999).

${ }^{9}$ M. K. Ferber, H. T. Lin, V. Parthasarathy, and R. A. Wenglarz, "Degradation of Silicon Nitrides in High Pressure, Moisture Rich Environments," to be published in the Transactions of ASME, 2000 (IGTI, ASME TURBO EXPO 2000, May 8-11, 2000, Munich, Germany).

${ }^{10}$ J. D. French and S. M. Wiederhorn, "Tensile Specimens from Ceramic Components," J. Am. Ceram. Soc., 79 [2] 550-552 (1996).

${ }^{11}$ H. T. Lin, P. F. Becher, and M. K. Ferber, "Improvement of Tensile Creep Displacement Measurements," J. Am. Ceram. Soc., 77 [10] 2767-70 (1994). 
${ }^{12}$ S. Zemskova, H. T. Lin, M. K. Ferber, and J. A. Haynes, unpublished results.

${ }^{13} \mathrm{C}$. W. Li and F. Reidinger, Microstructure and Tensile Creep Mechanisms of an in situ Reinforced Silicon Nitride," Acta Meter. Vol. 45, No. 1 pp. 407-421 (1997).

${ }^{14} \mathrm{~S}$. L. Hwang, H. T. Lin, and P. F. Becher, "Mechanical Properties of $\mathrm{B}_{-} \mathrm{Si}_{3} \mathrm{~N}_{4}$ Whisker Reinforced $\alpha$-SiAlON Ceramics," J. Mater. Sci., 30 (1995) 6023-6027.

${ }^{15}$ H. T. Lin and P. F. Becher, "High-Temperature Creep Deformation of Alumina-SiC Whisker Composites," J. Am. Ceram. Soc., 74 [8] 1886-93 (1991).

${ }^{16}$ S. M. Wiederhorn, D. E. Roberts, T.-J. Chuang, and L. Chuck, "Damage-Enhanced Creep in a Siliconized Silicon Carbide: Phenomenology," J. Am. Ceram. Soc., 71 [7] 602-608 (1988).

${ }^{17}$ E. Y. Sun, P. F. Becher, S. L. Hwang, S. B. Waters, G. M. Pharr, and T. Y. Tsui, "Properties of Silicon-Aluminum-Yttrium Oxynitride Glasses," J. Non-crystalline Solids, 208, 162-169 (1996).

${ }^{18}$ S. Sakka, "Oxynitride Glasses," Ann. Rev. Mater. Sci., 16, 29-46 (1986).

${ }^{19}$ M. K. Ferber and M. G. Jenkins, "Evaluation of the Strength and Creep-Fatigue Behavior of Hot Isostatically Pressed Silicon Nitride," J. Am. Cer, Soc., 75, 2453-2462 (1992).

${ }^{20}$ S. M. Wiederhorn, B. J. Hockey, and D. C. Cranmer, "Transient Creep Behavior of Hot Isostatically Pressed Silicon Nitride," J. Mater. Sci., 28, 445-453 (1993).

${ }^{21}$ W. E. Luecke, S. M. Wiederhorn, B. J. Hockey, R. E. Krause, Jr., and G. G. Long, "Cavitation Contributes Substantially to Tensile Creep in Silicon Nitride," J. Am. Ceram. Soc., 78 [8] 2085-96 (1995).

${ }^{22}$ I. Tanaka, G. Pezzotti, K. I. Matsushita, Y. Miyamoto, and T. Okamoto, J. Am. Ceram. Soc., 74 [10] 1886-93 (1991).

${ }^{23}$ I. Tanaka, K. I. Igashira, T. Okamoto, K. Niihara, and R. M. Cannon, , J. Am. Ceram. Soc., 78 [3] 673-679 (1995).

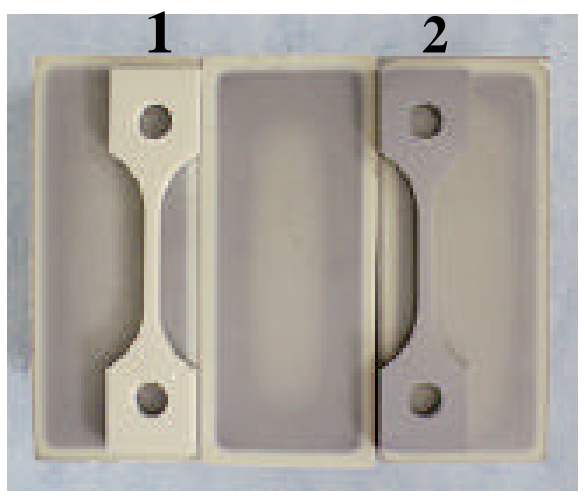

Figure 1. Photograph showing the cross section of as-sintered AS800 silicon nitride and dog bone type creep specimens machined from surface layer (1) and bulk region (2). 

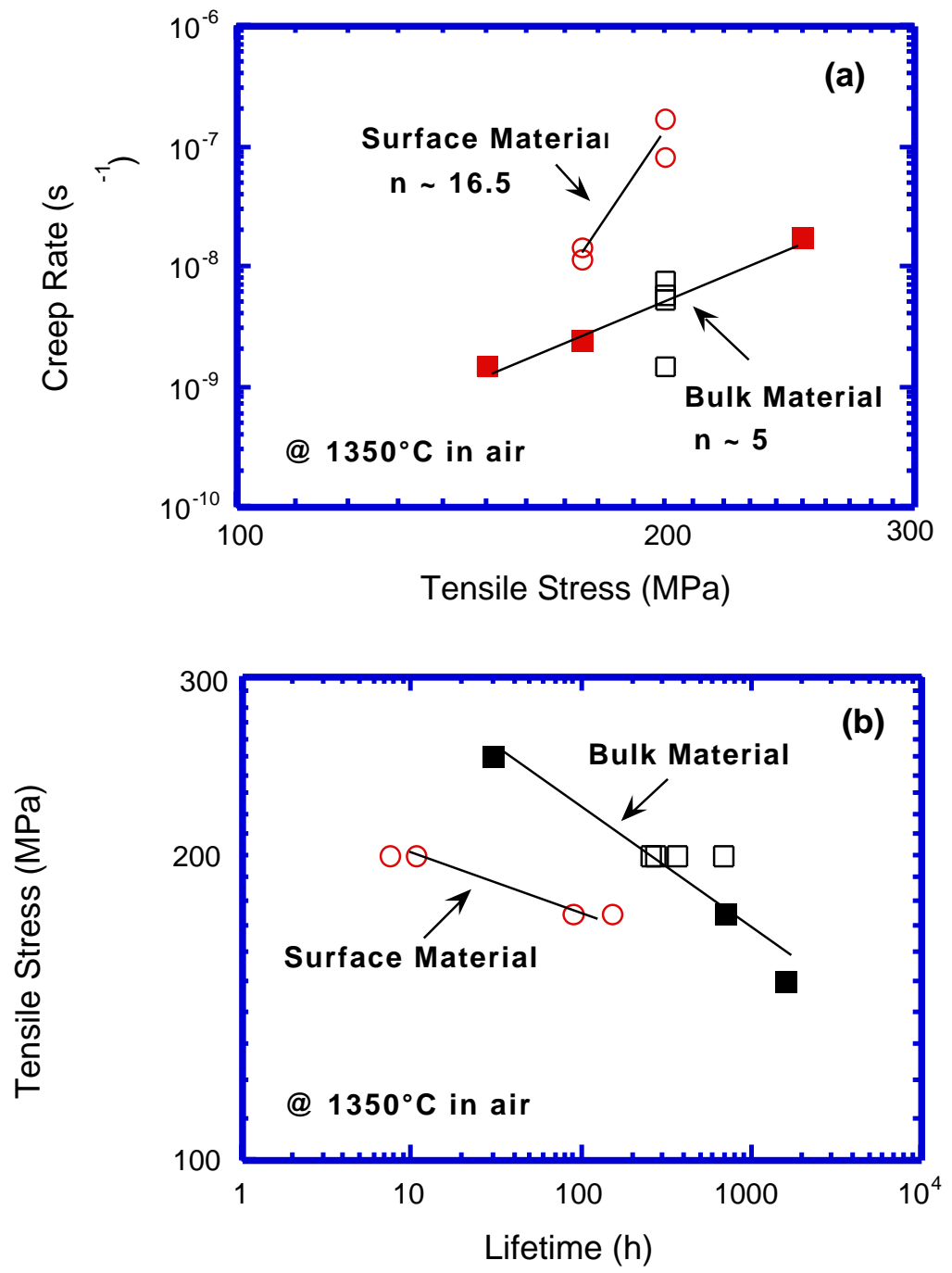

Figure 2. Plots showing (a) creep rate versus tensile stress results and (b) tensile stress versus lifetime results of AS800 silicon nitride material from surface layer and bulk region. 


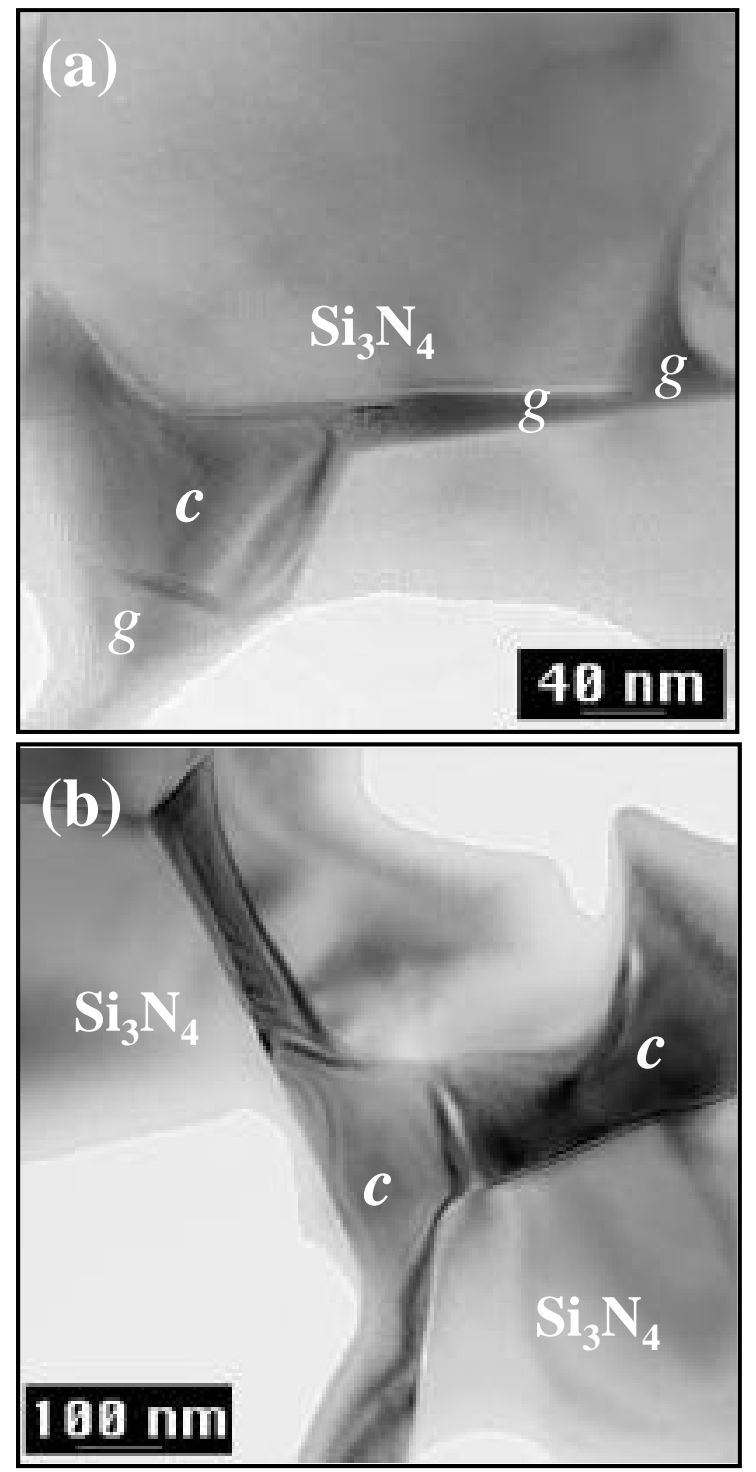

Figure 3. TEM micrographs of AS800 silicon nitride material from (a) surface layer and (b) bulk region. Note that the "g" and "c" denote the glassy and crystalline pockets, respectively. 

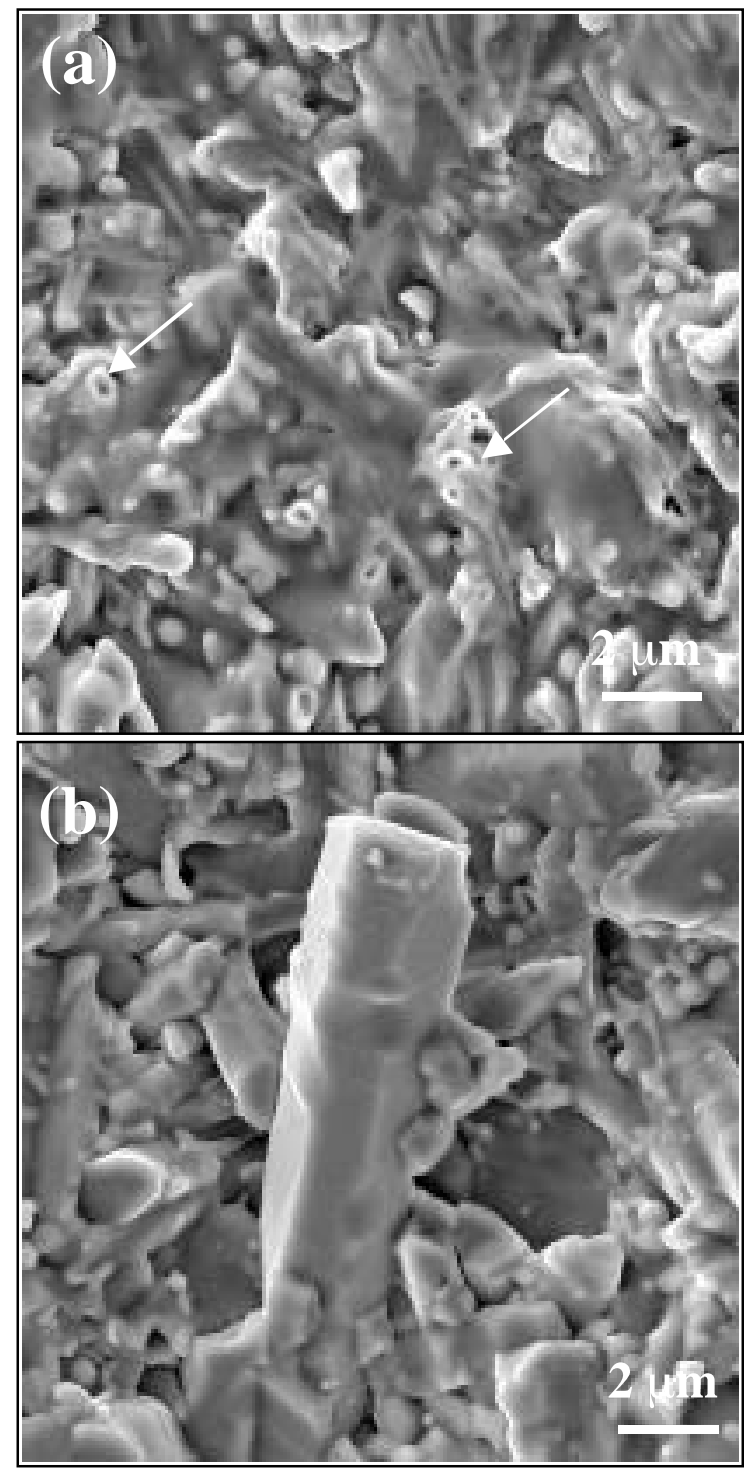

Figure 4. SEM micrographs of fracture surfaces of crept sample from (a) surface layer and (b) bulk region. Note that the arrows indicate the presence of gas voids due to oxidation of oxynitride glassy phase. 